\title{
Towards Reviving the Missing Noble Characteristics of Traditional Habitual Social Life: "Al-Farej "In Kingdom of Bahrain
}

\author{
${ }^{*}$ Dr. Islam H. El-Ghonaimy ${ }^{1}$ (D, MA. Mariam Haider Al-Haddad 2 \\ 1 \& 2 Department Of Architecture and interior design, College of Engineering, University of Bahrain, Bahrain \\ E mail: eelghonaimy@uob.edu.bh E mail: mariam.alhadad@hotmail.com
}

\begin{tabular}{|l|}
\hline A R T I C L E I N F O: \\
\hline Article history: \\
Received 16 January 2018 \\
Accepted 16 February 2018 \\
Available online 26 September \\
2018 \\
\hline Keywords: \\
Urbanization; \\
Social planning; \\
Sustainability; \\
Quality of life. \\
\end{tabular}

This work is licensed under a Creative Commons Attribution - NonCommercial - NoDerivs 4.0. "CC-BY-NC-ND"

\begin{abstract}
A B S T R A C T
For a long time, Social life in Bahrain was unique and positive. Public Participation and social cooperative with no reference of segregation or discrimination for long time. Regularly residences were gathering together to discuss the daily life, solving problems, discussing their economic and social issues with spirit of respecting human rights and civilization. In Bahrain, there were many elements, which were positively in city quality of life. For example, "Al-Farej" which is common name for space in old time in Bahrain, played the role of two main issues.

The research problem is that, unfortunately, most of the old part of Manama city, Capital of Bahrain, area suffer from losing the identity by modernization in many forms by urban developing. Consequently, day by day, the social life became different and lost most of noble characteristics of traditional habitual Social life. Bahraini heritage alive in the old area of Manama City, the area needs a node and a reference point for the community to gather in a better-built environment. Therefore, there is essential need for proposing solution to revive the brilliant of social life in Kingdom of Bahrain in term of gathering people for cultural events with economic return to keep the rich history and importance of the area and enhance the environment of the center of Manama.

The aim of the research is to propose solution to solve the missing of social life in old part of Bahrain by giving guidelines in representing "Al-Farej" in modern way matching with the modernization of life in Manama.
\end{abstract}

JOURNAL OF CONTEMPORARY URBAN AFFAIRS (2019), 3(2), 35-46.

https://doi.org/10.25034/ijcua.2018.4699

WWW.ijcua.com

Copyright (C) 2018 Journal Of Contemporary Urban Affairs. All rights reserved.

\section{Introduction}

The discreteness and positive credence of the social life in Bahrain had stood the test of time by virtue of public participation and social cooperation void of ethnical or racial discrimination. Since the birth of their community, the residents took to nonstereotypical assembling to settle upon their daily routine regulations, the daily life, sort out the encountered challenges, stipulating their individualistic socioeconomic codes owing to their inherited civilization. The difference lied in their cradle of eminence, for their variant yet solidary composition nourished their life quality.

*Corresponding Author:

Department Of Architecture and interior design, College of Engineering, University of Bahrain, Bahrain.

Email Address: eelghonaimy@uob.edu.bh 
For example, "Al-Farej" played the role of two aspects of premier importance; firstly the city acted as a prominent cultural center, which is an organization, building or complex that promotes culture and arts in Manama. It was common within Manama neighborhoods, to supply the community with arts and other related faculties. While the second was community gatherings centers, where the community members get in touch to perform some group activities, grant social support, gain public information, and secure other purposes. They may sometimes be open for the whole community or for a specialized group within the greater community. Commonly "AlFarej" had been organized by residencies within private, government-sponsored bodies, or activist-run. From the researchers' perspective, "Al-Farej" was the node of the ancient part of Manama city.

\subsection{Research Importance}

The research casts the light on the social and historical roots of Manama in general and Farej Al-Fadhel in specific for they once had the upper hand; thanks to their wealth and worth. Lamentably, these have been no more but decayed ruins after the negligence of the old social pattern and the traditional vernacular architecture of the deceased Bahraini style. In brief, the research comes up with a solution that will revive the Genius loci of the area by an architectural product, serving as a cultural community center at the heart of Manama, to revive the former domineering center of social and cultural values of the Bahraini communities.

\subsection{Research problem}

The disintegration of the urban fabric and architecture structure in the study area negatively affected the social traits, life quality and cultural values of the residents. Unfortunately, most of the old part of Manama area suffer identity loss by the rampant wave of modernization in many aspects of the action of its urban development. Consequently, each day passes by ripping off the remains of their distinguishing legacy, to mourn the loss of their bygone noble and traditional traits of their regular social life. Consequently, the research will explore problems in depth and find why applying modernism are commonly negative upon the study area.

\subsection{Research Goals}

Searching about a node "reference point" for the community which should be a building with social, culture, historical, economic, urban,...etc values. Moreover, introduce guidelines to enhance social residence life in the study area.

\subsection{Research Achievement}

"Al-Farej" at the heart of Manama gathers people for cultural events for financial profits is the key to enhance and revive the cultural and social of the center of Manama.

\subsection{Pilot study}

Studying the history of Manama in general while concentrating on Al Fadhel District (block 305), while Manama is the minor context, this research will review and analyze the urban, social, economic, architectural developments throughout its timeline past to present chronological sequence.

\subsection{Research Methodology}

i. Theoretical Phase: Data collection about old district from different resources about Manama throughout assembling old photos. Interviewing residence even elderly or recently residents in Al-Fadhel district or its novice immigrants for information retrieval from Al-Farej residents.

ii. Analytical Phase: gathered data and generating a timeline comprising the most important information

iii. Findings: After analyzing all data that were collected, design guidelines will be generated.

\section{Manama city, Capital of Kingdom of Bahrain}

\subsection{Location}

The kingdom of Bahrain is in the Gulf between Saudi Arabia and Qatar and is made up of 36 islands. The capital city of Manama serves as the hub of most of the population and economic activities. (Susan W, 2014). Before the development of the planning schemes and housing projects from the government, the island's inhabitants were dispersed in approximately fifty small settlements, which primarily included villages and hamlets. These villages were mostly located near the coast and in the interior part of the island near the springs. The settlements were based on the sources of natural springs and the presence of date palms. (Al-Nabi, 2012) 
Manama (Al Manamah), the capital, is located on the northeastern tip of the island of Bahrain. Moreover, Manama has the most commercial and cultural centers. Manama's expansion since 1960, when its population was only 62,000 and estimated the population of 152,000 in 1992. Most of the residences were in entire villages, fields, and palm and fruit groves located to the east, north, and south being incorporated as part of the urban sprawl. Recently, it also spread to the west through the reclamation of hundreds of hectares from the sea. (Pike, 2011). See figure 1\&2 in Appendix 'A'.

\subsection{Manama in the Decay Aftermath Era}

Historically Manama started developing as a gateway to the central Bahrain Island. The old Manama Port, the place on which the present Bab-Al-Bahrain building was erected during 1940, was the starting point for the growth of Manama and expanded eastwards towards Ras Ruman and westwards towards Naeem along the coast. Gradually it also extended towards the south. See figure ' 3 ', Appendix 'A'. The 1951 aerial photograph below shows the extent of growth of Manama as a dense contagious area extending to the south up to Sunni graveyard and up Hoora and Gudaibiya in the southeast. (Hamosh, Manama City Plans. Bahrain, 2009). Further, south and at southeast, there was barren land and at the southwest were palm tree gardens up to the sea. It should be noted that this district of Manama was built and developed by residents' needs abiding by no planning strategy. (Al-Nabi, 2012). See Figures' 4 to 9', Appendix 'A'.

\section{Identity and Urban Changes on Social Life}

The economic forces growth is developing with a growing number of new buildings projects in individualistic designs, leading to an urban development that is not guided by any general urban master plan but built up of separate case-by-case decisions instead. The rapidness and size of these projects in a grouping with shrinking restrictions have resulted in decreasing the quality of the built environment in Bahraini districts, mainly due to a deficit of technical and social infrastructure. The affected development of Bahrain's capital Manama is a witness of the deficiency of the current urbanization in old districts, where speculation-driven growth has led to fast urban progress without sufficient integration of the needs of native residents (Wiedmann, 2010). The urbanization process affects social life in many forms. In the study, the researcher will tackle the prime constituent of the country which is identity. The identity is acknowledged to be manifested in the urban pattern, architecture and social and economic activates in a named community. The following points will explore the significant changed locations.

\subsection{Identity of Vernacular Architecture in Bahrain}

The term identity, from the Latin word meaning (sameness), has become problematically defined throughout the history to mean differences as well as similarities, within traditional Western/Euro-centric approaches to the study of cultural identity; many people have been excluded as (others).

"The issue of architectural identity has been a global concern for many nations, especially in the last century"(Al-Bahar, 1985, p.98). Contemporary architecture in some Arab countries lost the traditional values, which encouraged the researcher to investigate these values and try to revive them in the contemporary architecture. According to Guibernau (2007) identity is defined as the continuity over time and differentiation from others taking into consideration the fundamental elements of national identity. Continuity springs from the conception of the nation as a historically rooted entity those projects into the future. Individuals perceive this continuity through a set of experiences that spread out across time and united by a common meaning, something that only 'insiders' can grasp. Differentiation stems from others leading to the distinction between members (those who belong) and "strangers", who are looked upon as'" the different' and, sometimes, 'the enemy'.

\subsection{Key Questions Concerning identity in Vernacular Aspects in Bahrain}

The critical questions concerning identity in Vernacular aspects in Bahrain are (Who am I?) (Who are we?). In fact, defining identity; as an interpretation of the self in both social and psychological terms that establishes what and where the person is. Mainly social relations and representations emerge within a system to present those identities. In Bahrain, there is a force to spread their national identity in national projects, as it is a subject of architectural significance. (Figure 10 \& 11) in Appendix 'A'. 


\subsection{Modernization and Lost Identity of the Vernacular Architecture in Bahrain}

The modernization development in all life fields as the Western cultural and intellectual invasion in the beginnings of the 20th century with the steady increase in population. Furthermore, in buildings, the local design principles were replaced by foreign standards that have changed the architectural and urban form, such as the human scale.

The urbanization affects the urban pattern and the related architectural designs. It directed towards using the western ideology rather than its local counterpart, in many of Bahrain cities. This reckless course of infringements towards the vehicular architectures adopted the westernization policies to the architectural design in different approaches. Most of the new building designs did not flow the ideology of the characteristic of vehicular architecture in Bahrain. Therefore, identity loss in the urban fabric is the ultimate result of that narrative. These areas have turned into a westernized environment as well as the most of the new buildings' forms and appeared with a new Western-style rather than a Bahraini one. Thus, they often failed to achieve environmental and humanitarian functions. In return, it negatively affects the social interaction between residences in general. High buildings are contradictory to the vernacular architecture as well buildings materials. See figure ' 12 ' in Appendix ' $A$ '.

\subsection{Bahrain National Planning 2030 and identity of the Bahraini Social life}

Referencing of Bahrain National Planning 2030, they stated that, The National Plan seeks to transform Bahrain into a prosperous and innovative city-state of the 21 st Century. In the time of petroleum discovery, many national master plans were created to serve the government in managing the economy of Bahrain. Many significant elements such as natural resources, inadequate housing, needs for specific zoning and insufficient public open space, low standard of transport infrastructure, and the need for improved education and depth economic issues and employment studies were addressed in these plans. The 2030 National Plan of Bahrain lays out ten key strategies that coordinate and focus development, control land speculation, protect resources, preserve historic and ecologically significant sites, integrate transport and ensure public access to open space and the waterfront. As shown in the report, the absence of concerning the modernization process and the negative impact of changing in urban fabrics and the architecture vocabulary upon social life in Bahraini residence. Figure' 13', Appendix 'A'.

\subsection{Symptoms of identity Loss in Bahraini Social life}

In conclusion, we can find that there is hybrid pattern fusing old traditional concepts with the new contemporary architecture. Consequently, many social changes resulted in the form of losing identity, losing some social spaces, decrease of public participation in developing the district and the loss of social interacting between districts residents. All these consequences led to delicate social fabrics. It should be noted that a large number of the local residences in the old part of Manama city moved out. As a result, the existing residences become a mixture of the native and novice, which cause identities losing most of their social identity and habits. Even in Bahrain 2030 National Planning Development Strategy, the focus upon developing the urban fabric and architecture is to adopt modernization with minor concern towards the impacts of architecture upon social life in Bahraini residents.

\section{4. "Al-Farej" in Manama city}

\subsection{Defending "Al-Farej"}

Studying "Al-Farej", which is a limited urban area, was due to the significance of social interacting occurred within old districts. Regularly "Al-Farej" was named is a relation to one of the prominent families in the area. The name of the Al-Farej is derived from the old craft of the pearl hole, which is a pearl breach. The nearest definition and the meaning of AlFarej is a small district or a neighborhood. Defending and exploring the importance of selecting Al-Farej came from the essential positive function of Al-Farej. Homogenous interweaving between different social background with different faiths, approaches and beliefs.

\subsection{Main features of "Al-Farej"}

The family and its structure as members were at all times the most important key factor in survival and success. Its social network helped weak members to survive, and its clear hierarchy with a tribal leader as the sheikh made for an active organization that defended common interests. The size and wealth of a family determined the power in different levels under its control and had led to 
the substantial identity. The Friday Mosque in "Al-Farej" as an urban element; became the most critical public arena for the community; besides its function as a religious center. It was often used as a court or school, particularly in smaller settlements. Its simple cubic form with an additional square, often enclosed by walls to form a courtyard, could be easily expanded according to the growth of the settlement. Thus, the size of the Friday mosque was often an expression of the number of inhabitants of "Al-Farej" (Wiedmann, 2010). The local market was the heart of urban fabric and considered significant element in intermediate with some Al-Farejs that most of the economic exchanges have regularly happened in considerable scale Families had their intimate space within AlFarej. They lived and grew to do their business and educated in this fringe, which is a microcosm of Bahrain. Integration and commutation were processed in the regular base, which carries diversity in its social fabric. Residences were living together with the original educational values in different levels and types and learn skills and handcrafts that were instilled within each other. They also grew up in the love of cooperation among all. The strong bonding of the children of Al-Farej, from the Al-farej urban pattern. See figure 14, in Appendix 'A'. Significance of "Al-Farej" in Manama city:

Long time in Manama city, Al-Farej had significant impact upon social and economic of Bahraini and non-Bahraini life. Reviving "Al-

Farej" in old parts of Manama city are to:

i. Socially;

a. Enhance the social life of current residences.

b. Attract the society again to the culturally rich districts and educate them about the values of these areas.

ii. Economically;

a. Enhance the commercial and trading life and the economy of current residences.

b. Make advantage of the "opportunity cost" (In microeconomic theory, it also known as alternative cost)

iii. Physical Environmental;

a. Revive the historical cultural principles.

b. Decrease aesthetic pollution and bridge the gap in Manama city.

\subsection{Changing Al-Farej Characteristics}

Recently, there was actively changing Al-Farej characteristics due to the changing of the urban fabrics, local emigration from the old families, changing of economic activities, and style of life instead of the local emigrants, most of the original families belong to their unique roles and homes. Extending from the depth of belonging to Al-Farej residential spirit. (Al Humar, 2012).

\subsection{Pilot study; Farej Al Fadhel (District); Manama City}

Farej Al Fadhel (Al Fadhel District) located in Manama, capital of the Kingdom of Bahrain, is adjacent to the Manama market and Farej Al Maharka, which was one of the main areas of the capital before its expansion in the 20th century. Unlike other regions of the Manama market, Farej al-Fadhel is inhabited by Omanis, Indians (especially the Bohras) and Jews, as well as Bahraini. Although, we can find that most of the Farej residents celebrate religious and national holidays together. Al-Fadhel District (Block 305), a minor context of Manama. See figure ' 15 ' in Appendix 'A'.

Recently, Al-Fadhel District suffers from many urban context problems in term of missing the open public spaces that were regularly used in meeting or gathering. These open spaces were used in meeting or convention in different circumstances as part of their traditional habits. Regularly, residences run conferences and gathering to manage their daily life in such areas. Solving problems and controlling the inters life process in their districts were sun as well, which regularly is operated by one of the selected old people with social and economic power.

Al-Fadhel District sustained missing these types of open spaces or buildings, lacking greenery and water surfaces, which once was schematic; loss of reference point for the old community (The old residents) nor the new city for social life and losing the historical and cultural heritage. Al-Fadhel residences run some social celebration events but in some multipurpose halls out the district which is meaningless compared with the original target of such gathering. See figure '16', in Appendix 'A'.

\subsection{Summary of the Inventory and Site Analysis of Farej Al-Fadhel}

Field survey and interviews with Farej Al-Fadhel residences were designed to examine the hypnosis that inhabitants are missing the spirit of Al-Farej in their life. The main observation are as follows:

\subsubsection{From the Social Perspective}

i. It was the town for many well-known families. 
ii. It consisted of Arab families, however, that the majority population is foreigners, but Manama is still an attraction and valued space for all Bahrainis.

iii. In religion events, Mostly people in the past go from one religious institution to another.

iv. Other religions respected and loved the Bahraini families and their religious activities as they fasted in Ramadan with the Muslims.

v. The mixed-use of a large percentage of buildings combined with the population density and minimal open space provides minimum conditions for a diverse urban life.

vi. The small plot size of most land holdings is also a factor in limiting the intrusion of large, single-use buildings which would threaten the current and historic diversity.

vii. Neighbors had a healthy relationship, and they were always together, so they never got bored.

viii. The first school for girls was built in AlFadhel district (Aisha Um-Almumineen School).

ix. The relationship between the families and their houses were always open to welcome anyone and were so intense.

$x$. It had one spring, which was in $\mathrm{Al}$ Fadhel mosque, and it had a pool, then residents made a showering area from to ab accessible by the residents to shower.

xi. They had two central Majlis (halls) for gatherings, cooking and welcoming guests from the Gulf countries. Figure 17, Appendix 'A'.

a. From the Economic Perspective

i. The top car trading, perfume business and famous for pearl trading owner lived there.

ii. Best teachers and best driving trainers lived there.

iii. Best ice cream, sambusa shop in the district, they were famous even in KSA.

iv. The first fire, trucks were brought there.

v. There is missing of having centers for traditional crafts and skills interacting, running the family production project or even managing public participation meetings to develop the district. vi. Near the Main Market, which was beneficial for the businesspersons, as they used to walk to their works without using Vehicles, minimum air and noise pollution are there.

b. From the Environmental Perspective:

i. It is the essential district as it is located in the heart of Manama, most of the residences manage the collecting and disposing of wastes there.

ii. A surprisingly large number of traditional houses also still stand in low-quality conditions while many of these have become almost invisible under a cloak of renovations and cosmetic changes considering environmental hazards.

iii. The overwhelming car traffic and undisciplined parking in the narrow, winding streets is also a significant force in speeding the decay of Manama causing different type of pollutions such as aesthetic, noise and air pollutions.

\subsection{Reviving Traditional Social Interacting of Al-Fadhel District}

From the previous justifications, Al-Farej idea is a community hub (node) inspired form Al-Farej concept following Bahraini heritage inspiration. A building in the heart of Manama that gathers people for different events and cultural activities to keep the rich history and importance of the area. It will be a place for the community to:

- Gather, talk, share knowledge and skills,

- Educate the new generation the artistry handcrafts.

Reference point for them to meet and gather inside the district in a suitable built environment instead of gathering outside carried by the Majlis concept. Al-Farej concept will be applied to keep the Bahraini heritage strong.

- Having facilities like a cultural café and restaurant to benefit the current community (economic value). See figure 18 in appendix ' $A$ '.

Therefore, the concept of the project is:

a. The revival: The old residents and elderly of the well-known families gather in halls inside the district to achieve the projects targets. The revival of the system of the Majlis for AlFadhel district to return as the core of meetings. The poets of Bahrain are famous for their poetic verses and carry on 
established traditions while also exploring new themes, as well as the art of storytelling. Using the pure Traditional Bahraini style in designing the spaces and elements of the building (Windows, doors, ... etc.).

b. The anchor: The project will be the node in the cultural activities map of the Municipality of Culture. A point of reference to the community. "AlFarej" idea should be installed on the Municipality of culture events calendar. "Al-Farej" idea aims to become anchor the history and cultural heritage in Manama consequently will not lose Manama identity, as well as attracting people again to Manama. See figure'19', in Appendix 'A'.

\subsection{Conclusions}

Bahrain was known since decades for its rich history and culture, the nest of all the deep and rooted history is anchored in Manama. Unfortunately, most of the old parts of Manama is suffering from the decay in its identity and heritage by modernization. The social life, which once was strong and formed the urban fabric of the cities, is changing making communities weak while losing the traditional habits and nodes. The old areas and neighborhoods in Manama city lack public spaces for residents to meet or gather for the revival of the traditional culture and heritage that once was rich in the districts. From the previous studies, due to the accelerated development, urbanization and globalization have negative impacts upon the vernacular and traditional built environment, which dramatically affect negatively upon social life of Bahraini within Manama city. Specifically, there is no clear identity for the district there. Moreover, there are no sufficient tries that deal with the traditional issues of Manama city. Consequently, the idea of reviving the Missing Noble Characteristics of Traditional Habitual Social Life should be examined by preserving architecture solution, which shows the identity of Vernacular issues in Bahrain. "Al-Farej "; is the Bright of Reviving the Brilliant of Social Life in the Kingdom of Bahrain.

Reviving the idea of Al Farej in a modern way has to respect technology, improved transportations, modern construction technologies and changing values and attitudes. Unquestionably, as observed from the field survey and the questionnaire for residences in the pilot study, the feelings of intimate relationships between builtenvironments and the residences have been splintered. As explained before, such building has to include social and economic activities that targeting the improvement of residences conditions and improve the physical environment of the districts.

\section{Findings - Design Guidelines}

Having the concept of Al-Farej will keep the Bahraini heritage alive in the area by the locals' contribution in the process of conservation. The district needs a hub (node) and a reference point for the community to gather in an excellent built environment that hosts cultural events and conserves history, traditions and culture.

The idea is a space that will be created and conserved for and by the old community. It will be a space that will be conserved and maintained and will be set as an example to encourage the conservation of the other ancient and historical parts of the areas. Facilities like a cultural café and restaurant will be introduced to benefit the current community and of economic value. Reference to the data analysis of the interviews, Al-Farej project, has to follow some fundamentals, such as:

a. Respect the history of the place and the existing historical buildings.

b. Reflect the economic significance of the area.

c. Respond to the social and religious activities.

d. Revive the greenery and water element, which once dominated.

e. Reflect the art and crafts which demolished.

f. Respond to the historical development of Manama.

\section{Acknowledgments}

Special thanks to Deanship of Graduate Studies and Scientific research for supporting this research paper via Scientific Research Project number 2014/7 and special appreciations for the respecting research assistant Architect Mohamed Elghoneimy, Architect Needa Javed and Architect Huma Mohamed for their efforts within the research.

\section{Conflict of interests}

The authors declare no conflict of interest. 


\section{References}

Al Humar, A. (2012). Al Farej; the litte image of bahrain. Al-Ayam. Retrieved from http://www.alayam.com/alayam/local/158 961/News.html

Al-Nabi, Mohammad Noor. (2012). The History of Land use and Development in Bahrain (1 ed., Vol. 1). Manama, Kingdom of Bahrain: Information Affairs Authority. Doi:978-99958$0-129-8$

Bahrain National Planning Development Strategy. (2007). Manama: SOM consultancy project for Bahrain. Retrieved from https://wiki.epfl.ch/lapastudio/documents/0910_BAH/Sourcebook/ BAH-SOM-Masterplan.pdf

BAHRAIN NATIONAL PLANNING DEVELOPMENT STRATEGY. (2007). Retrieved from SOM: https://www.som.com/projects/bahrain_na tional_planning_development_strategy

Dalia, H. E, Islam, H. E. (2008). Credential Buildings Approach for Preserving Architecture Treasure. Journal of the Gulf and Arabian Peninsula Studies, 34(130). Retrieved from https://search.ebscohost.com/login.aspx?d irect=true \& $\mathrm{db}=$ enr \&AN=34124658\&site=edslive

Dalia, H. E, Islam, H. E. (2016). Comparative Study for Developing Closed Vernacular Settlements in Egypt. IJRDO- Journal of Social Science and Humanities Research, $1(10)$, 82-105 https://ijrdo.org/index.php/sshr/article/view /401

Droodkin, R. (2007). Roman Residential District. Bahrain-old-photographs. Manama: farm2.static.flickr.com. Retrieved from http://intlhistory.blogspot.com/2013/01/bah rain-old-photographs.html

Elghonaimy, I. H. (2005). Historical values and architectural unique building authentication. Arab city magazine, 126, 50-66. Retrieved from www. ato.net

Freej Al Fadheel (2015). Retrieved Sep 24, 2017, from Photos and memories from Freej. Al Fadheel:

https://arar.facebook.com/freej.alfadheel

Gathering. (2007). Bahrain brethren. Manama. Retrieved from http://www.bahrainbrethren.com/UserFiles/ Image/photos/GATHERING/Bab\%20al\%20b ahrain.JPG

Hamosh, M. B. (2009). Manama City Plans. Bahrain (1 ed.). Manama., Kingdom of Bahrain: Bahrain.

Islam H. E, Mahdi J. (2010). Nations reminiscence and chronological buildings preservation,
Case study: Zayed House, kingdom of Bahrain. International convention on urban heritage in the Islamic states and its role in cultural, social and economic development. Riyadh, Saudi Arabia: Saudi Commission for Tourism and National Heritage.

Islam, H. E, Mohamed I. E. (2017). landscape Architecture significance in restoration Historical Areas, Case of old "Muharraq" city, Kingdom of Bahrain. 2nd Silk Cities International Conference, Reconnect Population to Urban Heritage in the Middle East \& Central Asia. 1. London, UK.: University College London. Retrieved from http://www.springer.com/gb/book/9783319 261133

Nabi, M. N. (2012). The History of Land use and Development in Bahrain (1 ed., Vol. 1). Manama, Bahrain: Information Affairs Authority Directorate of Government Printing Press.

Pike, J. (2011). urban Areas in Bahrain. Retrieved from Global Security: https://www.globalsecurity.org/military/worl d/gulf/bahrain-urban.htm

Susan. W, Jonathan. D, Eric. A, Andrea, H. (2014). Geospatial technologies and human rights project. Washington DC: American association for the advancement of science (AAAS). Retrieved from https://www.aaas.org/sites/default/files/GT HR_1_Introduction.pdf

Travelerpedia. (2007). Travelerpedia. Retrieved Aptil 20, 2018, from https://news.travelerpedia.net/destinations /\%D8\%A8\%D8\%A7\%D9\%84\%D8\%B5\%D9\%88 \%D8\%B1-\%D8\%A3\%D9\%81\%D8\%B6\%D9\%84\%D8\%A3\%D9\%85\%D8\%A7\%D9\%83\%D9\%86\%D8\%A7\%D9\%84\%D8\%AA\%D8\%B3\%D9\%88\% D9\%82-\%D9\%81\%D9\%8A-

\%D8\%A7\%D9\%84\%D8\%A8\%D8\%AD\%D8\%B 1 \%D9\%8A\%D9\%86/

Wiedmann, F. (2010). Post- oil urbanism in the Gulf. Stuttgart, Stuttgart, Germany: Städtebau Institut, FG SIAAL der Universität Stuttgart. Retrieved from https://www.researchgate.net/publication/ 279381714_Post-oil_urbanism_in_the_Gulf 
Appendix A: Figures

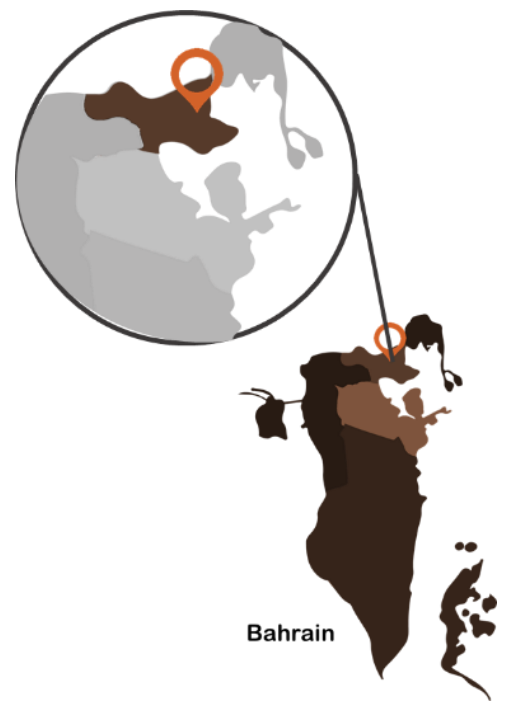

Figure 1: Principle springs of Bahrain (Al-Nabi, 2012)

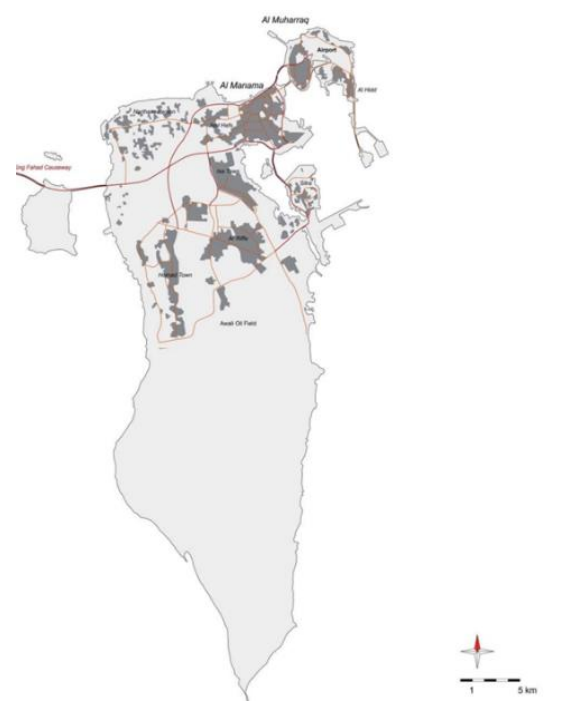

Figure 2: Settlement areas of Bahrain in 1996 (Wiedmann, 2010)
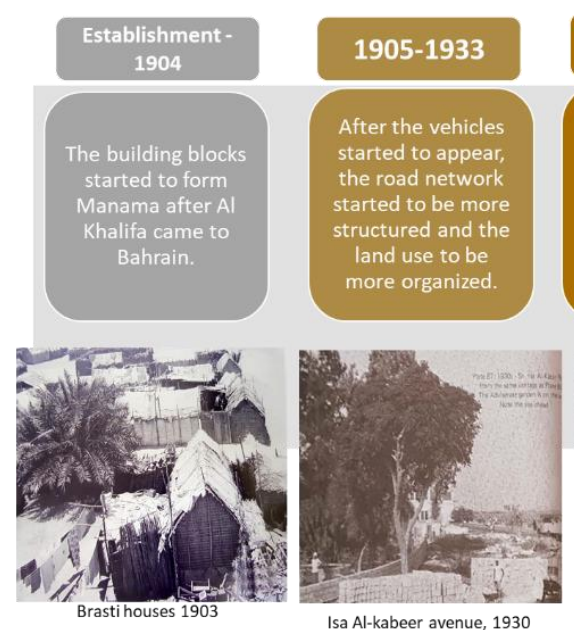
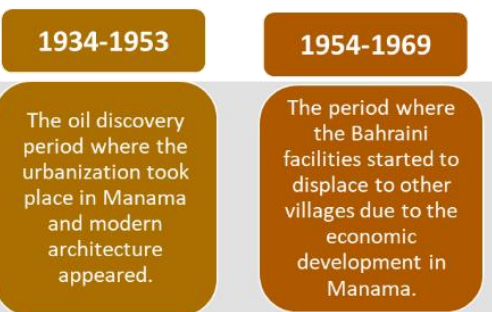

\section{0-1977}
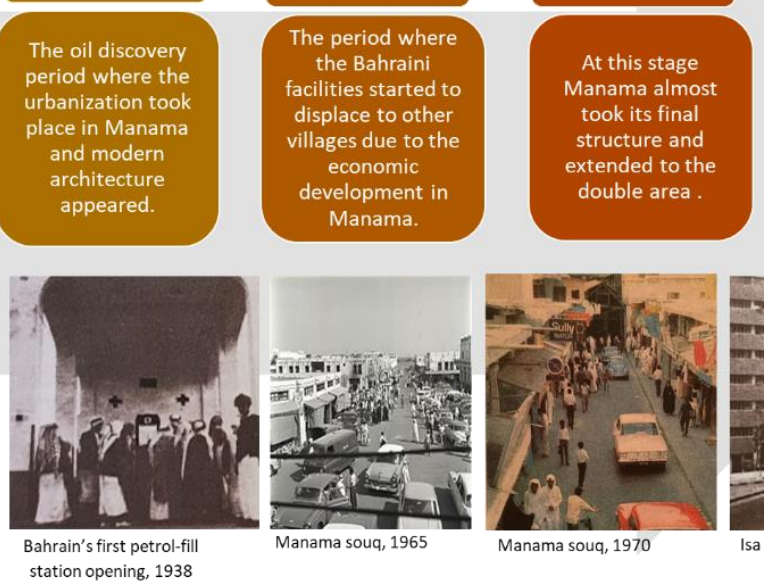

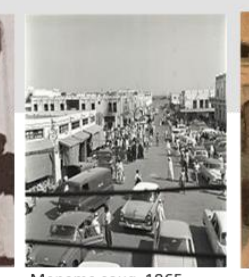

Manama souq, 1965

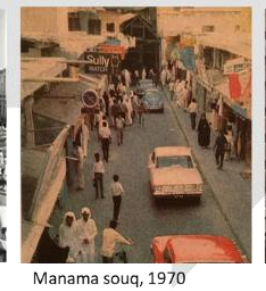

Manama souq, 1970 Bahrain's first petrol-fll
station opening, 1938

Figure 3: Manama developments timeline, source: Authors 


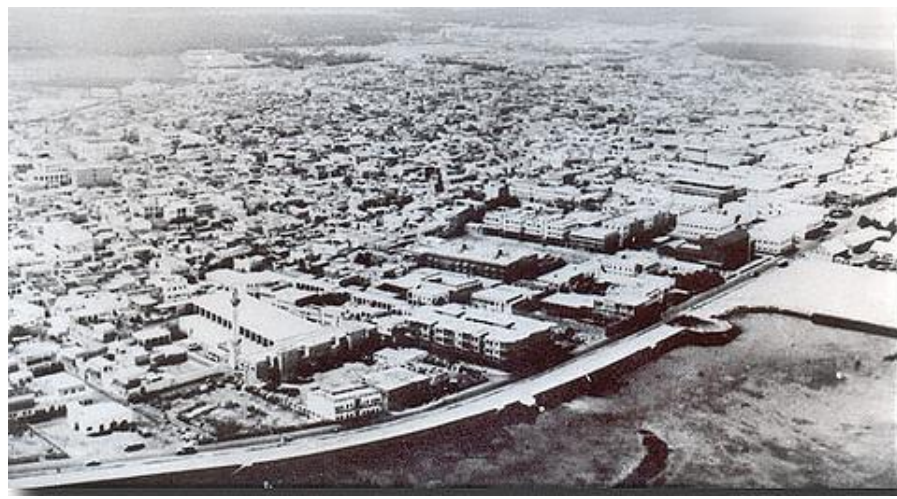

Figure 4: Aerial view of Manama, circa 1950s., Droodkin, (Droodkin, 2007)

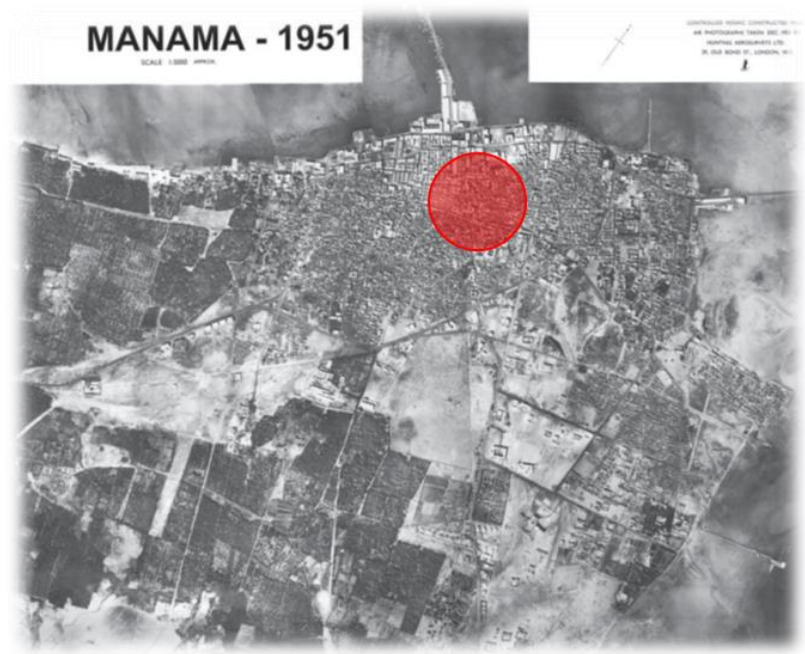

Figure 6: Topographic Map of Manama 1951. (Al-Nabi, The History of Land use and Development in Bahrain, 2012)

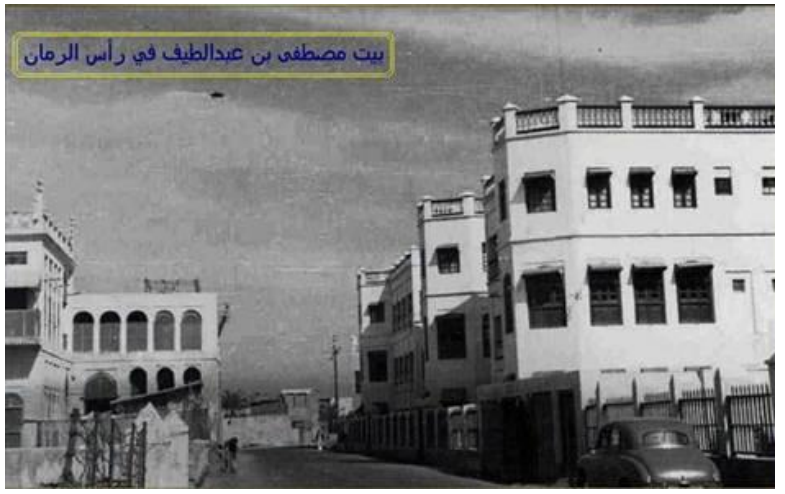

Figure 5: Ras Roman Residential district Droodkin, (Droodkin, 2007)

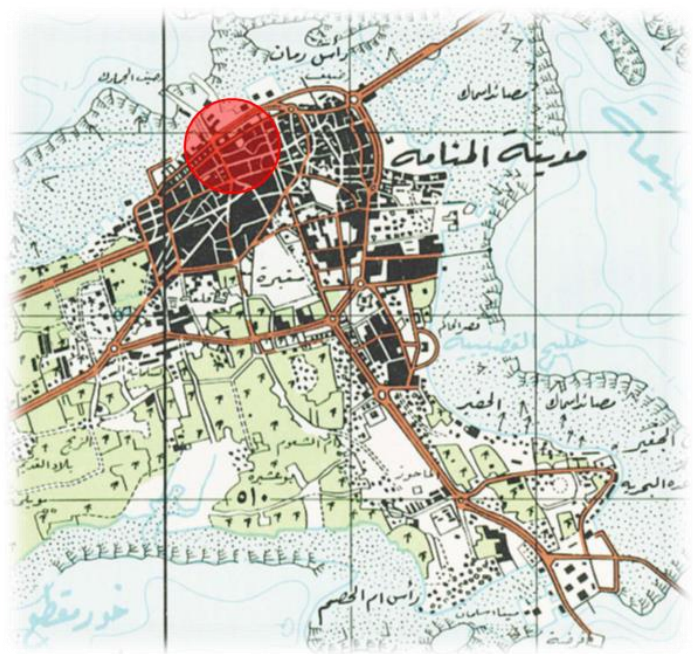

Figure 7: Topographic Map of Manama 1930

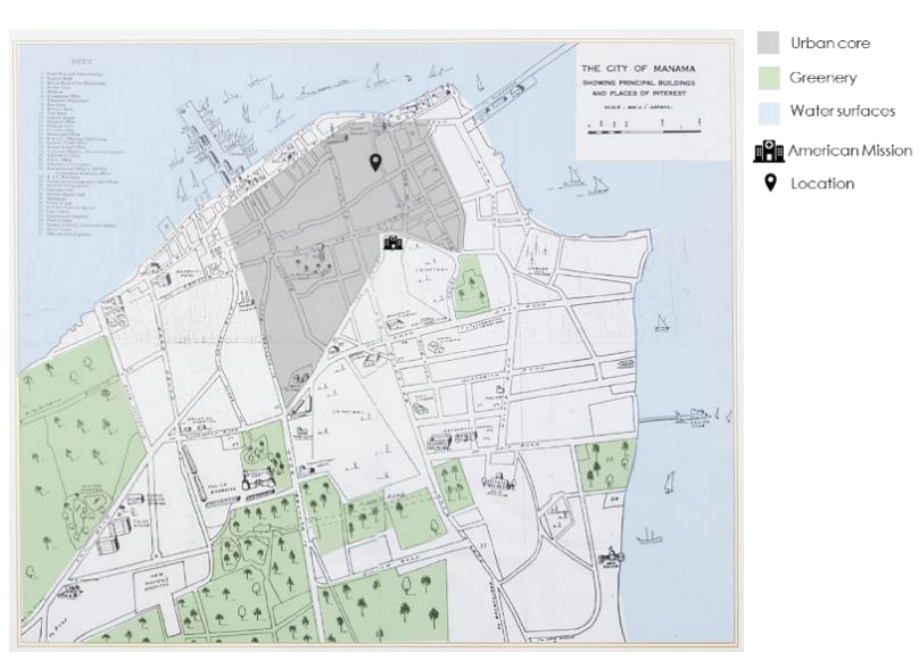

Figure 8: Existing soft scape in the British colony period end of 1960. (Hamosh, Manama City Plans. Bahrain, 2009)

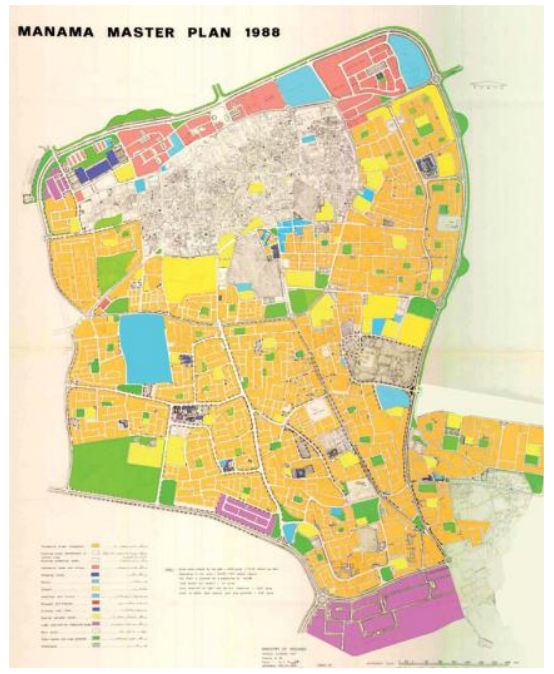

Figure 9: Implementation of Manama Master Plan 1988 (Al-Nabi, The History of Land use and Development in Bahrain, 2012) 


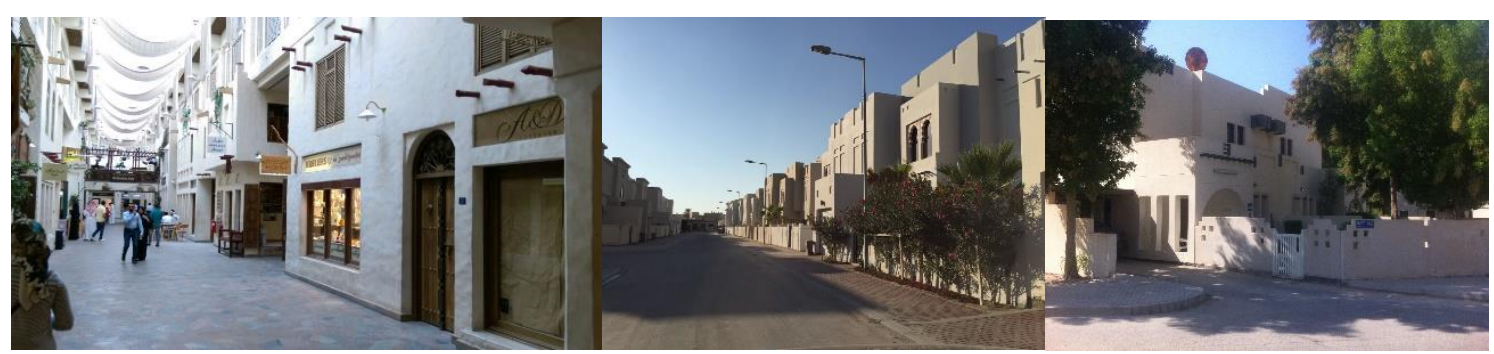

Figure 10. Commercial complex, Seef area Governmental Housing UoB campus (Authors 2018)
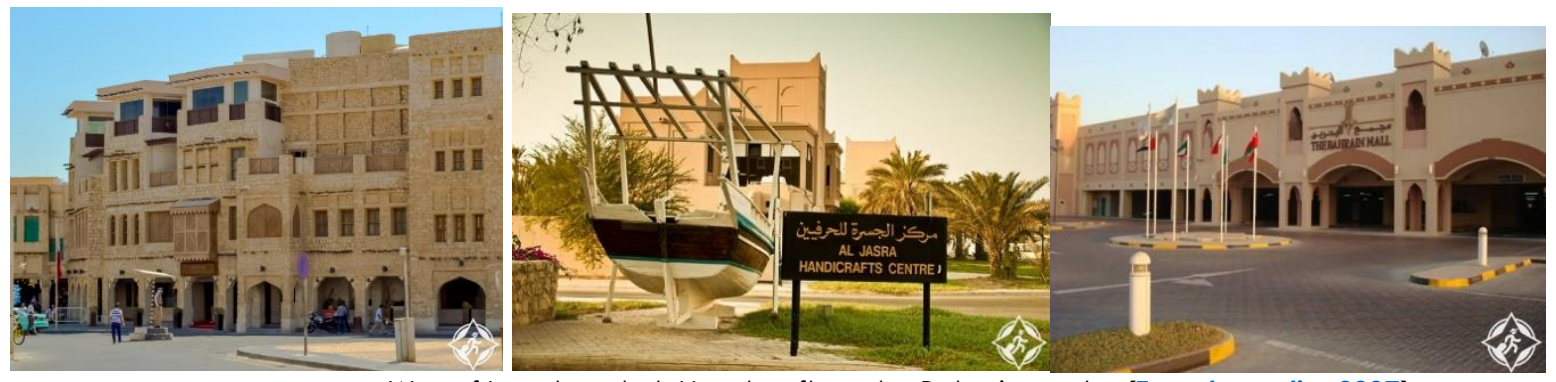

Waqef Local market Handcraft center Bahrain center (Travelerpedia, 2007)

Figure 11: Recalling the vernacular architecture in Bahrain
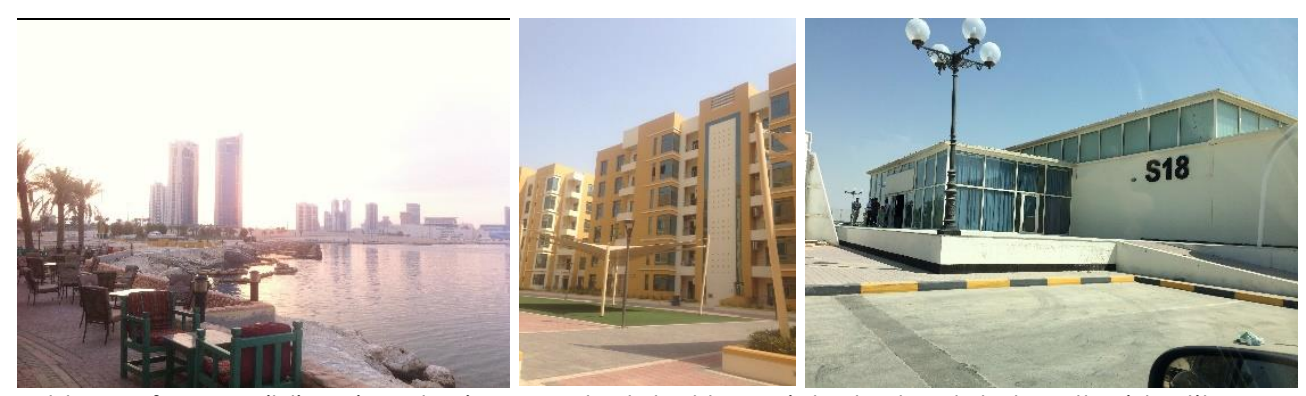

Figure 12: Different type of new Buildings in Bahrain are not related to social rotes leads to lose the identity

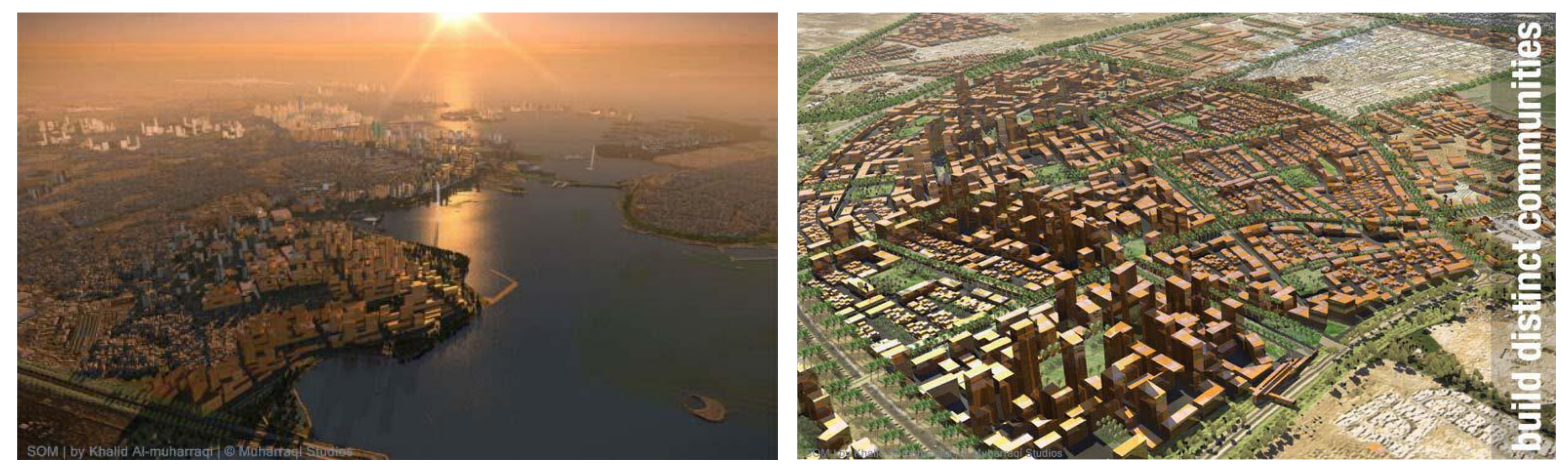

Figure 13: 2030 Bahrain National Planning Development Strategy. Manama .

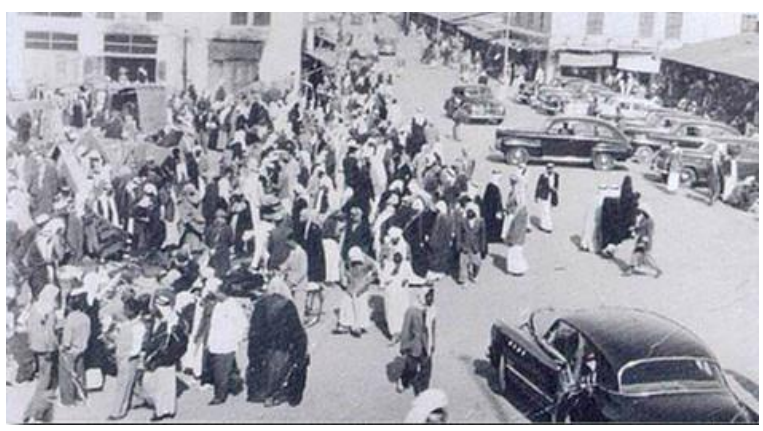

Figure 14: Vegetable Market in Manama 1930s-ish; Droodkin, https://www.blogger.com/profile/05791543764371993446 


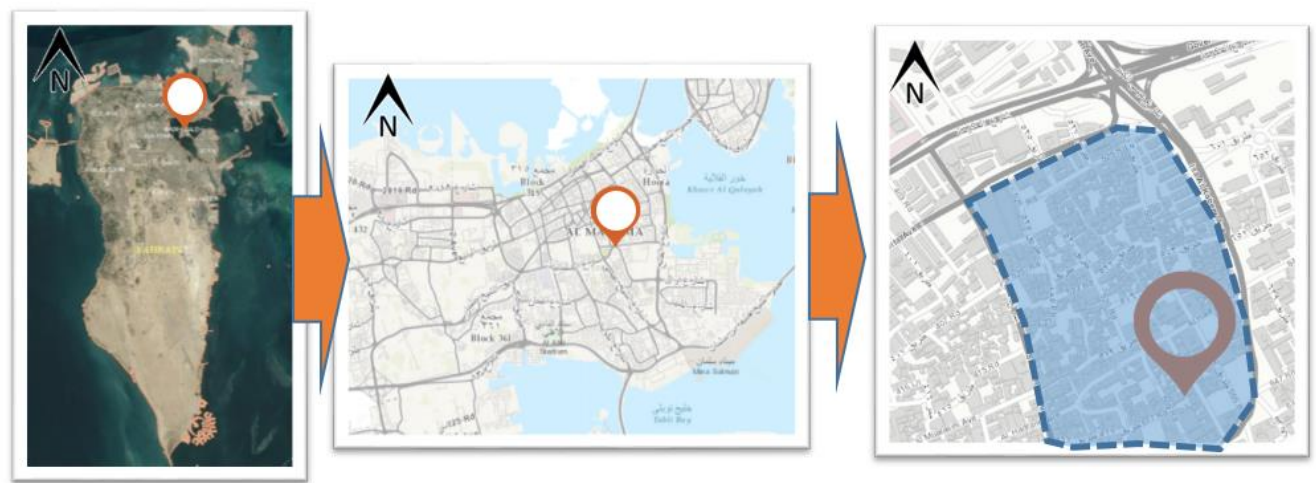

Figure 145: Al-Fadhel District relate to Bahrain and Manama Governorate map (google map 2018)

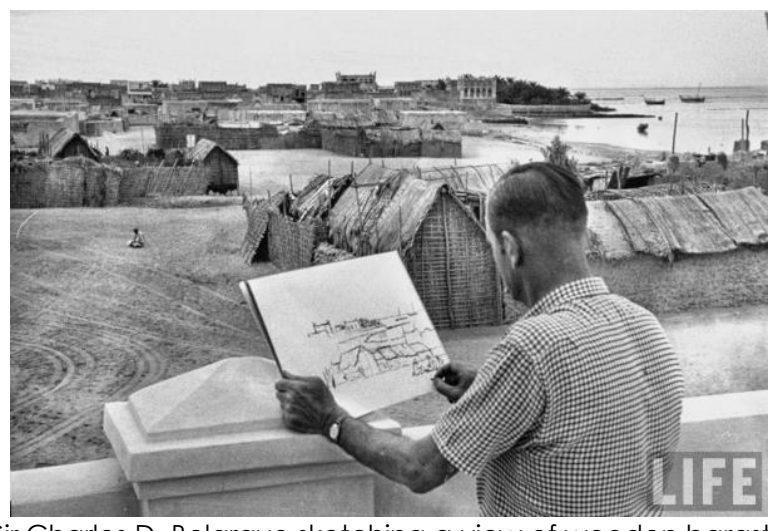

Sir Charles D. Belgrave sketching a view of wooden barastis in Manama.

Photographed by Walter Sanders, 1952

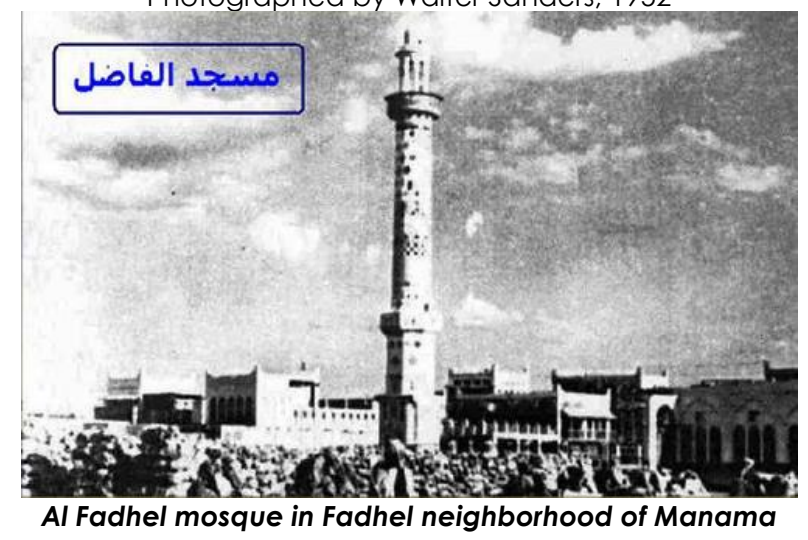

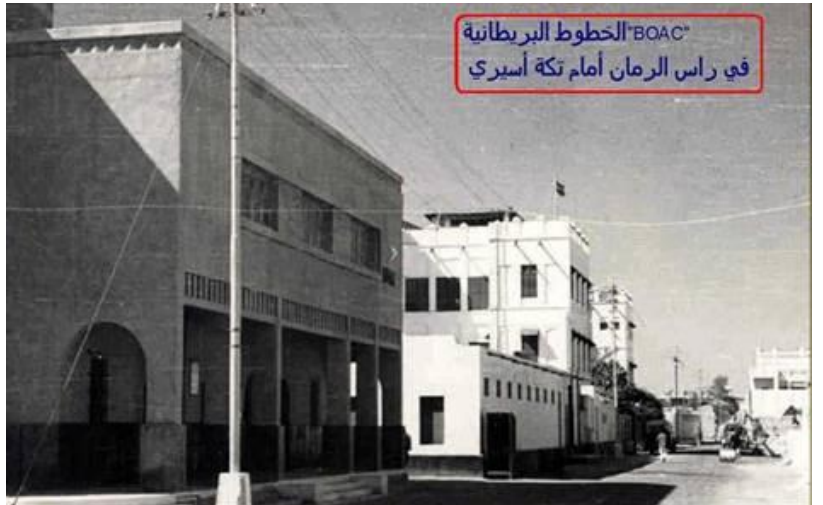

The office of the British Overseas Airways Corporation, in Ras Ruman

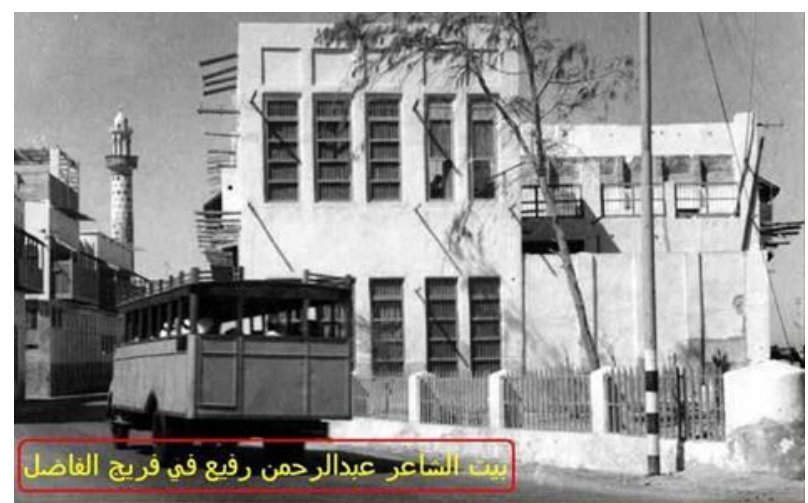

House of the poet Abdul Rahman Rafea, in the Fadhel neighborhood of Manama

Figure 16. Historical buildings and old life of Farej Al-Fadhel district

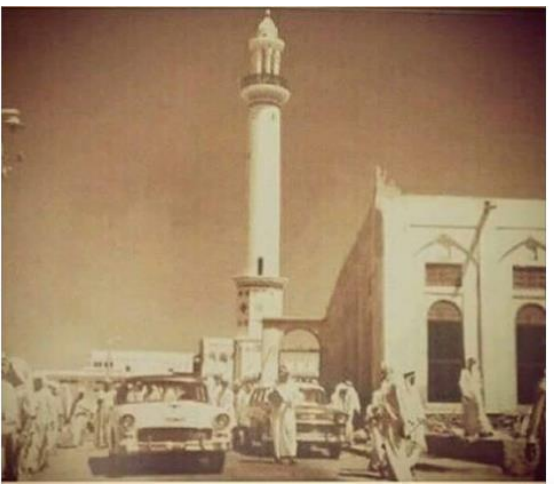

Figure 15. 1959 Freej Alfadheel/ (freej.alfadheel, 1959)

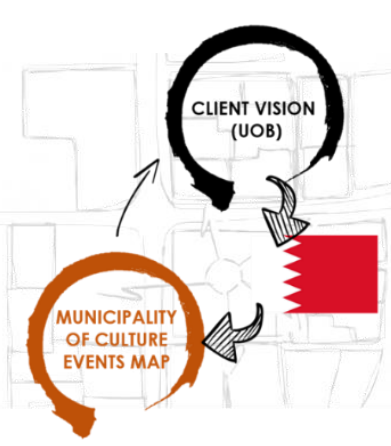

Figure 16. The anchor, source: Author 